\author{
Crossing the Border: International Journal of Interdisciplinary Studies \\ Volume 5; Number 2; 15 July 2017 \\ ISSN 2350-8752 (Print); ISSN 2350-8922 (Online)
}

\title{
EDITORIAL: \\ Teaching Learning through Interdisciplinary Approaches
}

There are many benefits of using interdisciplinary approaches in teaching and learning. One of the goals of teaching and learning is helping students to develop insights, problem solving skills and self-confidence. The teachers can bring them to their classroom is interdisciplinary approaches are used in the teaching learning process. In this way, interdisciplinary approaches help students develop their cognitive abilities such as skills and mental processes, which are necessary to solve the problems.

The interdisciplinary forms of instruction can be meaningful and lasting when the teachers impart students with a range of skills and insights about the learning process as they promote students' engagement in the classroom. So it fosters the acquisition of knowledge, promotes the integration of diverse ideas and provides insight about effective teaching. In addition, through the interdisciplinary teaching learning, students are expected to find interdisciplinary education engaging and interesting.

Interdisciplinary approaches also open academic discourses from a range of disciplines. In doing so, the students would be able to relate and contribute to the dialogue in a proper and meaningful way. Thus, the effective way to connect students with what the teachers want to share can be enhanced through interdisciplinary approaches. Not only this, students can have a variety of perspectives that can be utilized to understand the most of issues they come across. Thus, they find interdisciplinary forms of exploration more convincing and forceful, which promotes true learning.

In brief, the emerging popularity of interdisciplinary teaching and learning is due to the teachers and students' flexibility in the teaching learning process that are grounded in the student-centred pedagogy that many researchers have discovered in their studies.

The article "Non-native Accent, Favoritism and the Law" by Dr. Rahul Chakraborty deals with the questions such as how listeners exhibited preferential treatments towards speakers with non-native accent and how some non-native speakers are more immune to negative discrimination. Most importantly, the positive consequences and favouritism of non-native accent has been reviewed along with the legal provision available in the United States to counter accent based discrimination. So the article is about the accent bias against non-native speakers.

Dr. Min Pun's article "Anti-Racist Pedagogy and the Canonization of Toni Morrison" investigates the anti-racist approach in pedagogy in relation to the issues of representations of African Americans in American schools, curricula, and literary canon. It has considered anti-racist pedagogy as a correct approach to create a truly democratic society in a racist society like the United States of America. His paper has considered Toni Morrison as the most successful African American writer who has attained canonical status within the mainstream of both African American and American literature.

In their article "Displacement as a Diasporic Experience in V.S. Naipaul's A House for Mr. Biswas," the author Ram Prasad Rai focuses on the experiences of displace- 


\section{Crossing the Border: International Journal of Interdisciplinary Studies}

ment along with homelessness, alienation etc. faced by Mr. Biswas and other characters as they are from Indian diasporic community. For instance, Naipaul shows how Mr. Biswas more importantly along with other people as the generation of indentured labour immigrant parents in Trinidad suffer from homelessness, displacement, alienation etc.

In the article "Cybercrime and Security in Nepal: The Need for Two-Factor Authentication in Social Media," Chuda Bahadur Roka describes in detail about the cybercrime and security and authenticity related issues. According to him, with the rapid increment of internet users, risk of misuse such as cybercrime has increased through the use of internet.

Min Nepali, in his article "Humanity in BP Koirala's Sumnima", attempts to suggest that humans should make their effort for an ultimate harmony between humans and society. The author proves this idea through the study of BP Koirala's Sumnima. The author claims that Koirala, in his novel, believes that the essence of any civilization is the quest for a common humanity and not the zeal for cultural and religious orthodoxy as the protagonist Sumnima believes in cultural and religious orthodoxy and rejects other religions and cultures.

Similarly, the article "From Margin to Centre: A Study of Ennoblement in Shobha De's Socialite Evenings" by Dr. T.S. Ramesh and R. Vanitha aims to prove that how women in India tend to be transformed from margin to centre and how they want to be liberated physically and mentally and long for an independent identity by being aware of the choices open to them. For instance, the protagonists of Shobha De do not want to be docile, weak and dependent women, but want to be powerful and ready to revolt against unfair treatment to them.

Roshani Shrestha's article entitled "Formal Education for Personal and Professional Development: A Case Study of B.Ed. Female Graduates in Pokhara" aims to prove that formal Formal education acquired at university level has its direct correlation with the personal and professional development. She says that education, one of the key factors to human development and social change, helps to enhancing awareness of individual on political, social and economic situation. For instance, the female graduates of the study area have perceived that they are benefitted in their professional teaching and personal life from the knowledge and skill they acquired during their formal learning process. such as in getting ready for the classroom and rapport building. 